\title{
Failure of Secretin Release in Patients with Duodenal Ulcer
}

\author{
S. R. BLOOM, A. S. WARD
}

Br itish Medical fournal, 1975, 1, 126-127

\begin{abstract}
Summary
The release of secretin was studied in 12 normal subjects and 23 patients suffering from proved duodenal ulceration. After infusing acid directly into the duodenum mean plasma levels $( \pm$ S.E.M.) of secretin rose in normal subjects to $52.6 \pm 4.8 \mathrm{ng} / \mathrm{l}$ at six minutes but to only $37.5 \pm 3.6 \mathrm{ng} / \mathbf{1}$ in duodenal-ulcer patients, a significant difference. The impairment of secretin release was as great in patients with a recent onset as in those who had had symptoms of a duodenal ulcer for a long time, raising the possibility of it being a primary defect. Patients who smoked 20 or more cigarettes a day had a particularly reduced secretin release, in accord with the greater incidence of ulcers in heavy smokers.
\end{abstract}

\section{Introduction}

Though secretin was the first hormone to be discovered (Bayliss and Starling, 1902) its role in human pathology has hardly been investigated. Administration of small amounts of secretin stimulates the pancreas to flood the duodenum with an alkaline watery juice (Farooq et al., 1974), and there are no other physiologically important mechanisms controlling this flow of alkaline juice (Winship and Robinson, 1974). Secretin levels thus control the speed and degree of acid neutralization in the duodenum.

In patients who have a duodenal ulcer not only is the mean gastric acid production increased (Baron, 1963) but also duodenal acid neutralization is considerably impaired (Berk et al., 1942; Wormsley, 1969). Ulcers in the duodenum are acid dependent and will heal if a high $\mathrm{pH}$ can be maintained. As pancreatic sensitivity to secretin in patients with duodenal ulcer seems to be normal (Banks et al., 1967; Wormsley and Mahoney, 1967) we investigated whether the release of secretin from the duodenal mucosa is impaired.

\section{Patients and Methods}

Twelve normal subjects, 10 of them men (mean age 38 years, weight $71 \mathrm{~kg}$ ), and 23 patients with duodenal ulcer, 21 of them men (mean age 42 years, weight $68 \mathrm{~kg}$ ), were studied. The presence of a duodenal ulcer was subsequently confirmed by operative inspection. Normal subjects were volunteers free of gastrointestinal symptoms who were either inpatients awaiting minor surgery or members of the hospital staff.

A fine polyvinyl tube was passed on each subject and screened into position so that the holes for infusion lay in the distal

\footnotetext{
Thorn Institute of Clinical Science, Middlesex Hospital, London W1P 7PN

S. R. BLOOM, M.B., M.R.C.P., M.R.C. Research Fellow (Present appointment Honorary Consultant and Lecturer, Department of Medicine, Roya Postgraduate Medical School, London W.12)

University Surgical Unit, Sheffield Royal Infirmary, Sheffield S6 3DA

A. S. WARD, M.B., F.R.C.S., Lecturer in Surgery
}

duodenum (Ward, 1973). Gastric secretin was maintained throughout the study by an intravenous infusion of pentagastrin (6 $\mu \mathrm{g} / \mathrm{kg} / \mathrm{h})$. Gastric juice was collected in 10-minute aliquots by continuous suction on a Salem sump tube, passed so as to lie in the gastric antrum. After a steady secretory plateau had been reached secretin release was stimulated by a five-minute intraduodenal infusion of $40 \mathrm{ml}$ of $0 \cdot 1-\mathrm{M} \mathrm{HC1}$ containing $2 \%$ polyethylene glycol (PEG) at $37^{\circ} \mathrm{C}$.

Gastric juice volume and $\mathrm{pH}$ were measured directly and the hydrogen ion concentration was estimated by titration to $\mathrm{pH} 7$. PEG was measured turbimetrically (Malawer and Powell, 1967). Loss of gastric juice into the duodenum was measured in six normal and eight duodenal-ulcer subjects by the phenol-red recovery method of Hobsley and Silen (1969).

Blood samples were taken with 1,000 kallikrein inactivating units heparinized aprotinin (Trasylol) per $\mathrm{ml}$, immediately centrifuged, and the plasma stored deep frozen. Plasma secretin was assayed by a radioimmunoassay (Bloom, 1974) using antibodies raised to pure synthetic secretin and ${ }^{125} \mathrm{I}$ label attached to the $\mathrm{N}$-terminal histidine of pure natural or synthetic secretin. No cross-reaction was noted with vasoactive intestinal peptide, gastric inhibitory peptide, or glucagon. The assay could detect changes of $9 \mathrm{ng} / 1$ between individual plasma samples with $95 \%$ confidence.

\section{Results}

The intraduodenal $\mathrm{HCl}$ caused a mean drop ( \pm S.E.M.) in gastric acid output of $1.9 \pm 0.5 \mathrm{mmol}(\mathrm{mEq})(37 \pm 10 \%)$ from a mean plateau level of $4.8 \pm 0.6 \mathrm{mmol} / 10 \mathrm{~min}$ in nine normal subjects and of $1.9 \pm 0.4 \mathrm{mmol}(23 \pm 5 \%)$ from $7.4 \pm 0.5 \mathrm{mmol} / 10 \mathrm{~min}$ in 19 duodenal-ulcer patients. Three normal subjects and four patients were excluded from these acid data because they had an unsatisfactory gastric collection owing to either duodenogastric reflux, as indexed by PEG recovery in the gastric juice (one normal and three duodenal-ulcer subjects), or failure to achieve a stable secretory plateau (two and one subjects respectively). The acid output was significantly higher in the patients with duodenal ulcer $(P<0.01)$, but the absolute fall in acid output after intraduodenal $\mathrm{HCl}$ was the same in the two groups.

The plasma secretin response to intraduodenal acid is shown in the diagram. Duodenal-ulcer patients had a lower mean plasma secretin level than the normal subjects throughout the test, and this was significant at all points $(P<\cdot 02)$. The phenolred studies indicated a mean pyloric loss of gastric acid during pentagastrin stimulation of $12.3 \%$ in normal subjects and $9.9 \%$ in patients. Thus, the initial secretin levels were not true resting values but represented a significant degree of stimulation due to the leak of acid into the duodenum. The area under the secretin curve (see fig.) for the 10 minutes after introduction of acid was $413 \pm 29 \mathrm{ng} / \mathrm{J} / \mathrm{min}$ in normal subjects and 273 $\pm 23 \mathrm{ng} / \mathrm{l} / \mathrm{min}$ in patients $(\mathrm{P}<0.001)$. Thus, the total secretin response in the patients with duodenal ulcer was $66 \%$ of that in the normal subjects. Duodenal-ulcer patients who had had symptoms for less than 10 years (seven patients, for a mean of 3.3 years) had a 10 -minute secretin release of 274 $\pm 38 \mathrm{ng} / \mathrm{l} / \mathrm{min}$ and those with a history of over 10 years ( 15 patients for a mean of 16.4 years) had a very similar secretin release of $273 \pm 31 \mathrm{ng} / \mathrm{l} / \mathrm{min}$. The 11 duodenal-ulcer patients who gave a clear history of smoking less than 15 cigarettes a day (mean 6) had a secretin release of $312 \pm 34 \mathrm{ng} / \mathrm{l}$ / min, and the nine who smoked 20 or more a day (mean 23) 


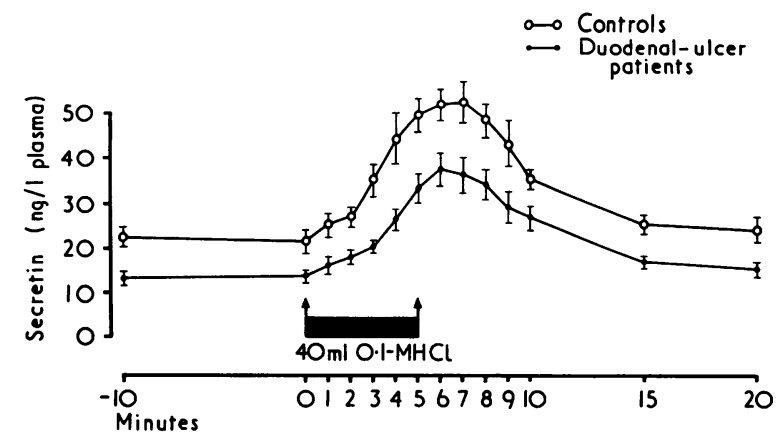

Mean plasma secretin concentrations during five-minute infusion of $4 \mathrm{mmol}$ of $0 \cdot 1-\mathrm{M} \mathrm{HCl}$ into duodenum. Bars are S.E. of Mean.

had a release of $216 \pm 26 \mathrm{ng} / \mathrm{l} / \mathrm{min}$. Both values were significantly different from those of normal controls, some of whom were also smokers $(\mathrm{P}<\cdot 05$ and $\mathrm{P}<\cdot 001$ respectively) and also from each other $(P<\cdot 05)$. There was no significant difference in secretin release between smokers and non-smokers in the controls. Secretin release was unaffected by age or weight in the range studied. No correlation was apparent between the amount of secretin released by intraduodenal acid and either the degree of gastric acid inhibition $(r=0.054, n=28)$ or the level of the initial gastric acid plateau $(r=0.006, n=28)$.

\section{Discussion}

We wanted to investigate whether the plasma secretin level, which is a major regulator of acid neutralization in the duodenum, was abnormal in patients with a duodenal ulcer. The results clearly show that secretin release was significantly reduced in this group. The radioimmunoassay used to measure plasma secretin was both sensitive and specific and a significant individual rise of secretin was recorded after intraduodenal acid in all the 35 subjects studied. The intraduodenal acid load given to stimulate secretin release, $4 \mathrm{mmol}$ over five minutes, was less than has been used in previous gastric inhibitory studies (Johnston and Duthie, 1964) and was similar to the maximal gastric acid secretory rate. To see whether this secretin release could be related to inhibition of gastric acid the subjects were studied during gastric stimulation by a pentagastrin infusion. The pentagastrin produced a plateau of gastric acid secretion which, as found in previous studies (Johnston and Jepson, 1967), was significantly higher in the duodenal-ulcer patients than in normal subjects. The infused intraduodenal acid resulted in an equal inhibition of gastric acid secretion in the two groups in absolute terms, but as a percentage inhibition it was smaller in the duodenal-ulcer patients. The intraduodenal acid load released significantly less secretin in patients with duodenal ulcer than in normal subjects though duodenal-ulcer patients are known to neutralize duodenal acid more slowly (Berk et al., 1942; Wormsley, 1969). The same relationship was seen before the intraduodenal acid infusion, when a lesser stimulation from leakage of gastric juice occurred. Unfortunately, true resting secretin levels are below $5 \mathrm{ng} / \mathrm{l}$ and cannot be reliably measured (S. R. Bloom and M. G. Bryant, unpublished). In spite of the association of greater acid output and failure of secretin release in duodenal-ulcer patients there was no individual correlation between these two values. Patients who smoked heavily were found to have a greater impairment of secretin release and this could have a connexion with the known higher incidence of duodenal ulcer in smokers (Edwards et al., 1959; Hammond, 1964).
The cause of duodenal ulcer is unknown but it possibly results from either a relative excess of acid in the duodenum attacking the mucosa or a defect in normal mucosal protection and repair. An excess of acid in the duodenum could be the result of excess gastric acid production or a failure to remove or neutralize it in the duodenum or both. A mean increase of gastric acid production in established duodenal-ulcer patients has been shown (Wormsley, 1974), but two-thirds of patients still fall within the normal range (Hassan and Hobsley, 1971). Several workers have reported impaired acid neutralization in the duodenum (Berk et al., 1942; Wormsley, 1969) in duodenalulcer patients owing to decreased pancreatic bicarbonate production. It was argued that this was the result of failure of endogenous secretin release (Fiddian-Green and Hobsley, 1974) because when exogenous secretin was administered the pancreatic bicarbonate response was completely normal (Banks et al., 1967; Wormsley and Mahoney, 1967; Petersen, 1970). Whether high gastric acid output could be the result of impaired secretin release seems more doubtful as infusion of high physiological levels of secretin does not acutely alter gastric-acid output (Ward and Bloom, 1974). Deficient secretin release, however, suggests the possibilitity of failure of other intestinal hormones, such as bulbogastrone (Anderson, 1973), which are physiological gastric acid inhibitors.

An unanswerable question at the moment is whether the impaired secretin release is a cause or a consequence of duodenal ulceration. The fact that the short-history patients had as great a deficit as the long-history patients may perhaps argue against the consequence theory. Many of the duodenal-ulcer patients had a secretin release within the normal range but the standard deviation of the group as a whole was as small as in the normal subjects. This implies that the duodenal-ulcer patients are fairly homogeneous and may all have some degree of secretin impairment. Thus, in spite of requiring greater pancreatic bicarbonate output to neutralize a larger gastric acid load, patients with a duodenal ulcer have an impaired secretin release, and this must be an adverse factor in their condition.

We thank Mrs. S. J. Mitchell and Mrs. E. S. Brocklehurst for technical help. Pure porcine secretin was very kindly donated by Professor V. Mutt, Stockholm, Sweden, and pure synthetic secretin by Dr. R. Geiger, Farbwerke Hoechst A.G., West Germany. Support was received from the British Diabetic Association and the Peel Medical Research Trust. S.R.B. was in receipt of an M.R.C. Fellowship.

\section{References}

Anderson, S. (1973). Annual Review of Physiology, 35, 431.

Banks, P. A., et al. (1967). Gastroenterology, 53, 575.

Baron, J. H. (1963). Clinical Science, 24, 357.

Bayliss, W. M., and Starling, E. H. (1902). Proceedings of the Royal Society, $69,352$.

Berk, J. E., Rehfuss, M. E., and Thomas, J. E. (1942). Archives of Internal Medicine, 70, 959 .

Bloom, S. R. (1974). British Medical Bulletin, 30, 62.

Edwards, F., McKeown, T., and Whitfield, A. G. W. (1959). Lancet, 1, 196. Faroog, O., Sturdevant, R. A. L., and Isenberg, J. I. (1974). Gastroenterology, 66, 204.

Fiddian-Green, R., and Hobsley, M. (1974). British fournal of Surgery, 61, 330.

Hammond, E. C. (1964). Fournal of the National Cancer Institute, 32, 1161. Hassan, M. A., and Hobsley, M. (1971). British fournal of Surgery, 58, 171. Hobsley, M., and Silen, W. (1969). Gut, 10, 787 .

Hobsley, M., and Silen, W. (1969). Gut, 10, 787.
Johnston, D., and Duthie, H. L. (1964), Gut. 5, 573.

Johnston, D., and Duthie, H. L. (1964), Gut. 5, 573.
Johnston, D., and Jepson, K. (1967). Lancet, 2, 585.

Malawer, S. J., and Powell, D. W. (1967). Gastroenterology, 53, 250.

Malawer, S. J., and Powell, D. W. (1967). Gastroenterology, 53, 250.

Petersen, H. (1970). Scandinavian fournal of Gastroentero
Ward, A. S. (1973). British fournal of Surgery, 60, 533.

Ward, A. S., and Bloom, S. R. (1974). Gut, 15. 889.

Winship, D. H., and Robinson, J. E. (1974). Gastroenterology, 66, 181.

Wormsley, K. G. (1969). Scandinavian Fourna, of Gastroenterology, 4, 717. Wormsley, K. G. (1974). Gut, 15, 59 .

Wormsley, K. G., and Mahoney, M. P. (1967). Lancet, 1, 657. 